\title{
A importância da poesia digital no acesso à literatura
}

\begin{abstract}
Resumo:
Este artigo visa a discutir a respeito dos textos poéticos que são veiculados na rede social Instagram e como eles podem ser incorporados nas aulas de literatura, discorrendo a respeito das novas tecnologias e da relação do ensino que a escola oferece com esses fatores, além de tentar compreender melhor o letramento literário e como ele está ligado diretamente ao ensino de literatura através da relação com os textos literários estudados. A metodologia utilizada baseou-se em pesquisas bibliográficas sobre o tema e questionário respondido por professores de Língua Portuguesa e Literatura e alunos dos períodos finais do curso de Letras de Caruaru e algumas cidades próximas, bem como de análises feitas em perfis do Instagram que divulgam poesia autoral e de autores já conhecidos. Os resultados nos mostraram o despreparo de muitos docentes para lidar com as demandas da sociedade moderna. Recorremos aos teóricos Todorov (2009), Cosson (2014, 2015) e Martins (2016) para embasar nossa pesquisa.
\end{abstract}

\author{
Palavras-chave: \\ Literatura. Escrita digital. Letramento.
}

\section{The importance of digital poetry in accessing literature}

\begin{abstract}
:
This article aims to discuss about the poetic texts that are broadcast on the social network Instagram and how they can be incorporated into literature classes. Talking about the new technologies and the relationship of teaching that the school offers with these factors, in addition to trying to better understand literary literacy and how it is directly linked to the teaching of Literature through the relationship with the studied literary texts. The methodology used was based on bibliographic research on the theme and questionnaire answered by Portuguese Language and Literature teachers and students from the final periods of the Letters course in Caruaru and some nearby cities, as well as analyzes made on Instagram profiles that disseminate poetry author and authors already known. The results showed us the unpreparedness of many teachers to deal with the demands of modern society. We used the theorists Todorov (2009), Cosson (2014, 2015) and Martins (2016) to support our research.
\end{abstract}

\section{Keywords:}

Literature. Digital writing. Literacy.

1 Professora de Língua Portuguesa, formada em Letras/Espanhol pela Faculdade de Filosofia, Ciências e Letras de Caruaru (FAFICA), pós-graduanda em Literatura Brasileira pela Faculdade Metropolitana. E-mail: alessandra_monteiro_10@hotmail. com ORCID: 0000-0003-2413-3871 


\section{La importancia de la poesía digital para acceder a la literatura}

\section{Resumen:}

Este artículo tiene como objetivo discutir sobre los textos poéticos que se publican en la red social Instagram y cómo se pueden incorporar a las clases de literatura. Hablar de las nuevas tecnologías y la relación de la docencia que ofrece la escuela con estos factores, además de intentar comprender mejor la alfabetización literaria y cómo se vincula directamente con la enseñanza de la Literatura a través de la relación con los textos literarios estudiados. La metodología utilizada se basó en la investigación bibliográfica sobre el tema y cuestionario respondido por profesores y estudiantes de Lengua y Literatura Portuguesa de los períodos finales del curso de Letras en Caruaru y algunas ciudades cercanas, así como análisis realizados en los perfiles de Instagram que difunden la poesía del autor y autores ya conocidos. Los resultados nos mostraron la falta de preparación de muchos profesores para hacer frente a las demandas de la sociedad moderna. Utilizamos a los teóricos Todorov (2009), Cosson (2014, 2015) y Martins (2016) para apoyar nuestra investigación.

Palabras clave:

Literatura. Escritura digital. Letramento.

\section{Introdução}

Quando nos debruçamos sobre o conceito de letramento, nos deparamos com a perspectiva de que nem todos que sabem ler conseguem interpretar o que leem, assim quando vamos para a discussão do letramento literário, associamos as práticas de leitura aos textos considerados literários, sendo estes formados em sua maioria por escrita simbólica e ficcional. Várias problematizações surgem disso, mas o que nos impulsionou nesta pesquisa foram o crescimento das novas tecnologias, a proliferação de textos literários nas redes sociais e qual a relação que eles têm tido com o ensino de literatura.

E quando falamos em escola e no currículo do que deve ser ensinado em literatura, principalmente no ensino médio, onde esta é acrescentada ao conjunto de matérias que devem ser estudadas, nos deparamos com a questão do que deve ser escolhido como conteúdo para essas aulas. Sendo as aulas pautadas basicamente nas escolas literárias e suas características, é comum os docentes escolherem apenas obras desses períodos específicos para trabalharem com os alunos. Longe de querer negar a importância de Machado de Assis ou Clarice Lispector, por exemplo, nas aulas de literatura, acredita-se que a escola deve ser o espaço para a discussão e ampliação dos conhecimentos e de acesso à literatura, por isso há a necessidade da inclusão de novos e diversos textos literários junto aos que já são estudados.

Apesar do tema não ter tanto material, percebemos o crescimento das pesquisas na área das tecnologias associada ao ensino, pois, atualmente, é praticamente impossível desenvolver qualquer coisa desassociada de algum modo da tecnologia. Sendo a escola uma instituição social, é essencial que ela acompanhe as mudanças sociais, por isso a importância das pesquisas nessa área.

Levando em consideração que atualmente a internet e as redes sociais têm exercido um fascínio principalmente nos jovens, que são o público das escolas, temos por objetivo discorrer sobre a recorrência da literatura no Instagram ${ }^{2}$ enquanto rede social, e em como o meio digital pode ser aliado ao ensino de literatura. Nesse sentido, queremos abordar tanto a escrita de poesia autoral quanto a divulgação de poesia de autores conhecidos e sua veiculação nesta rede social,

2 Instagram. Disponível em: https://www.instagram.com/. Acesso em: 01 ago. 2020 
associar esse tipo de escrita ao letramento literário e relacionar essa discussão à metodologia do ensino de literatura nas escolas.

Para tanto, baseamo-nos nas discussões já levantadas por Todorov (2009) sobre a importância do ensino de literatura e sobre a importância da discussão adequada dos textos literários em sala de aula, bem como em Cosson (2014a), um teórico bastante conhecido por suas contribuições na área do letramento, principalmente o letramento literário, e por fim Martins (2016) nos auxilia na discussão sobre o Instagram e os textos literários presente nele.

\section{Metodologia}

Para desenvolver o tema, optamos pelas pesquisas bibliográfica e de campo, de acordo com Severino (2007). Desenvolvemos o tema de maneira explicativa e descritiva, utilizando métodos tanto quantitativos, com o questionário sobre o ensino de literatura com perguntas a respeito do que os entrevistados tinham de formação para lidar com tecnologia em sala de aula, se achavam que novos escritores podiam ser incluídos nas aulas de literatura, o nível de conhecimento deles na plataforma da rede social Instagram, entre outras perguntas, que por sua vez foi respondido por docentes de língua portuguesa do ensino fundamental II e médio, bem como um dos entrevistados é docente de ensino superior, e graduandos em Letras nos períodos finais que já estavam desenvolvendo atividades em sala de aula através dos estágios, todos esses da região da cidade de Caruaru-PE e cidades próximas, como qualitativos, através da discussão dos preconceitos ainda existentes no uso dos textos literários.

No meio digital, a pesquisa de fontes foi realizada nas publicações do Instagram nos perfis @lucaoescritor, sendo esta uma página de poesia autoral e, portanto, trazendo a discussão sobre novos escritores e a possibilidade de interpretação de suas poesias na escola, e @literaturaesoamor, que por sua vez traz posts ${ }^{3}$ com poesias de autores já conhecidos e serve para a reflexão sobre uma nova forma de acesso às obras literárias dentro do meio tecnológico em que as obras passaram a ser de domínio público. Este artigo é voltado principalmente para os docentes de língua portuguesa, tendo em vista que com o aumento das novas tecnologias faz-se necessário pensar em como incorporá-las ao ensino, e também por ser este grupo quem lida diretamente com os desafios do processo de letramento.

\section{Letramento literário e ensino}

Para chegarmos ao assunto principal deste trabalho, precisamos levar em consideração alguns conceitos pertinentes, o principal é o que se entende por letramento. Kleiman (2001, p. 19) vai defini-lo como "um conjunto de práticas sociais que usam a escrita, enquanto sistema simbólico e enquanto tecnologia, em contextos específicos, para objetivos específicos". Apesar de haver vários conceitos e especificações para a palavra letramento, seu significado principal está voltado à leitura e à escrita. Com relação ao que seria literatura, é uma ampla discussão que por fim não se chega a um conceito único. Contudo, para os fins da nossa pesquisa, podemos compreender essa junção entre letramento e literatura, ou seja, o letramento literário como

um processo de aprendizagem, resultado da experiência do leitor com o texto, simultaneamente solitário e solidário porque implica negociar, reformar, construir, transformar e transmitir o repertório que recebemos de nossa comunidade como literário. (COSSON, 2015, p. 182).

3 Publicações de imagens feitas pelo usuário da rede social. 
Neste contexto, podemos compreender comunidade como escola, e ao refletirmos sobre ela e, por conseguinte, sobre o ensino de literatura, nos deparamos com diversos problemas. Cosson (2014a), em um de seus livros sobre letramento literário, chama atenção para uma pesquisa feita entre professores de linguagens, e que resultou no seguinte:

Para muitos professores e estudiosos da área de Letras, a literatura só se mantém na escola por força da tradição e da inércia curricular, uma vez que a educação literária é um produto do século XIX que já não tem razão de ser no século XXI. A multiplicidade dos textos, a onipresença das imagens, a variedade das manifestações culturais, entre tantas outras características da sociedade contemporânea, são alguns dos argumentos que levam à recusa de um lugar à literatura na escola atual. (COSSON, 2014a, p. 14).

Esta afirmação nos leva à compreensão de que um dos grandes problemas da falta de incorporação de novas tecnologias e de modificações no ensino de literatura tem sido, justamente, a negação de sua atualidade. Quando o ensino de literatura é galgado apenas em datas de início e fim das escolas literárias, principais características de cada uma delas e obra mais importante, de fato, ela torna-se apenas mais uma das ramificações da matéria História, fugindo completamente do que pode ser pensado e ensinado a partir dos textos literários e do contexto em que eles foram criados, além da relevância que eles têm para a atualidade. E toda essa visão desconsidera que

A prática da literatura, seja pela leitura, seja pela escritura, consiste exatamente em uma exploração das potencialidades da linguagem, da palavra e da escrita, que não tem paralelo em outra atividade humana. Por essa exploração, o dizer o mundo (re)construído pela força da palavra, que é a literatura, revela-se como uma prática fundamental para a constituição de um sujeito da escrita. (COSSON, 2014a, p. 11).

O problema dessa metodologia é o que Todorov (2009, p. 27) afirma: "na escola, não aprendemos acerca do que falam as obras, mas sim do que falam os críticos", ou seja, as noções críticas institucionais já predefinidas são o que orientam como as obras devem ser analisadas em sala de aula. E nesse contexto, acaba não havendo espaço para a inserção de novas obras, de novos textos literários e de novas formas de conceber literatura. Entretanto, quando olhamos para o que é proposto por esse tipo de letramento percebemos

que o objetivo maior do letramento literário escolar ou do ensino da literatura na escola é nos formar como leitores, não como qualquer leitor ou um leitor qualquer, mas um leitor capaz de se inserir em uma comunidade, manipular seus instrumentos culturais e construir com eles um sentido para si e para o mundo em que vive. (SOUZA; COSSON, 2011, p. 106).

A Base Nacional Comum Curricular (BNCC), que orienta o currículo das escolas em nosso país, expõe a importância da utilização de diversos recursos na metodologia de ensino de linguagens, onde literatura também está inserida. Sobre isso, destacam que

é importante que os jovens, ao explorarem as possibilidades expressivas das diversas linguagens, possam realizar reflexões que envolvam o exercício de análise de elementos discursivos, composicionais e formais de enunciados nas diferentes semioses - visuais (imagens estáticas e em movimento), sonoras (música, ruídos, sonoridades), verbais (oral ou visual-motora, como Libras, e escrita) e corporais (gestuais, cênicas, dança). Afinal, muito por efeito das novas tecnologias da informação e da comunicação (TDIC), os textos e discursos atuais organizam-se de maneira híbrida e multissemiótica, incorporando diferentes sistemas de signos em sua constituição. (BRASIL, 2017, p. 478, grifo nosso). 
E nisso percebemos que há o incentivo do uso da multimodalidade e da intersecção entre diversos meios para que se possa chegar ao objetivo principal, que é a efetividade do ensino.

\section{A utilização de poesia do Instagram nas aulas de literatura}

Há vários anos que a internet se tornou um espaço de interesse das pessoas de diferentes idades, consequentemente, as redes de interação social estão cada vez mais cheias de pessoas interessadas em compartilhar conceitos, opiniões, preferências pessoais e aspectos da vida pessoal. Com o crescente sucesso das variadas redes sociais, é notável a participação dos jovens nesses espaços virtuais e, principalmente, é evidente a abertura que elas têm para manifestações escritas e visuais. Isso tem sido aproveitado pelos usuários para divulgar seus trabalhos, que vão desde a venda de artigos feitos a mão, à produção de textos e poesias autorais.

A pergunta que tem nos movido é: se as redes sociais fazem parte da vida da nossa sociedade, como a escola pode incorporar aspectos delas nas aulas, uma vez que o objetivo da escola é justamente formar um indivíduo apto para o convívio em sociedade, um ser crítico, que consiga pensar e definir suas prioridades?

Diante disso, surgem diversas problematizações, como a questão social da comunidade em que a escola está inserida, a ausência de recursos básicos, para dizer o mínimo, e consequentemente a falta de recursos para o uso da tecnologia na escola. Nossa discussão está atrelada à possibilidade de subversão do comum nas aulas de literatura com a inserção de textos que estão para além dos cânones.

Sabemos que há toda uma discussão e também uma discriminação no processo de escolha das obras utilizadas no ensino de literatura. Geralmente são escolhidas obras que são pertencentes a escritores já consagrados na literatura nacional e/ou internacional, ou apenas autores mencionados nos livros didáticos e, portanto, pouco se utiliza textos ou obras de novos escritores, ou até de escritores antigos, mas que não são tão conhecidos.

Quando refletimos sobre isso, percebemos que a escola é o espaço em que deve haver abertura para o contato com os mais diversos tipos de textos literários, que não deve haver uma preocupação por parte dos alunos por não compreenderem esses tipos de textos e achar, erroneamente, que isso está destinado apenas para os intelectuais ou à "elite". Sobre a importância da prática de leitura em conjunto na escola, Cosson (2014b, p. 149) vai nos dizer que "quando lemos juntos compartilhamos o entendimento daquele texto e também de protocolos de leitura, participamos de e construímos uma comunidade de leitores".

Outra problematização referente ao uso de textos na aula de literatura está ligada ao que é considerado poesia. Nas escolas, a tendência é considerar a metrificação e as regras sobre rima, ritmo, versificação, entre outros. O problema não está na utilização destes métodos, mas na consideração de que a poesia só seria algo que se encaixasse nesses padrões, ou ainda, em formas livres, porém feita por escritores renomados. A discussão é para que seja aberto espaço para novas formas de poesia na escola, e que essas sejam tão válidas quanto as que já são do cânone literário. Os poetas da antiguidade clássica e das escolas literárias tiveram, e ainda têm, muita importância na escrita de poesia, mas eles não podem ser tomados como parâmetros para análise das poesias contemporâneas. Não podemos esquecer que

depois do Clássico poético sucederam-se, no mundo ocidental, muitos momentos e manifestos em favor de novidades, de modelos ou antimodelos, mas que dialogassem com o tempo em que se vive e de acordo com o contexto onde os sujeitos se encontram inseridos. (SILVA; SANTOS; COELHO, 2016, p. 5). 
Entre esses momentos, podemos relembrar as vanguardas europeias, por exemplo, a Semana de Arte Moderna de 1922 aqui no Brasil, que tinha por objetivo romper com o que era produzido em termos de literatura em sua época. Assim sendo, a manifestação da escrita de poesia na internet e nas redes sociais são um advento pertencente às manifestações da era contemporânea. E, portanto, deve servir como conteúdo para as aulas de literatura. E ainda de acordo com a BNCC, essas manifestações na escola são tomadas como parte das habilidades que devem ser exploradas, ocorrendo do seguinte modo:

a ampliação de repertório, considerando a diversidade cultural, de maneira a abranger produções e formas de expressão diversas - literatura juvenil, literatura periférico-marginal, o culto, o clássico, o popular, cultura de massa, cultura das mídias, culturas juvenis etc. - e em suas múltiplas repercussões e possibilidades de apreciação, em processos que envolvem adaptações, remidiações, estilizações, paródias, HQs, minisséries, filmes, videominutos, games, etc. (BRASIL, 2017, p. 492).

Com isso, observamos a rede social Instagram, que tem sido um grande meio de divulgação de textos literários e poesia, por se tratar de um espaço para publicação de imagens, exatamente pelo meio visual atrair bastante o interlocutor, e esta rede propiciar a combinação de texto e imagem em uma só postagem ${ }^{4}$. Em uma pesquisa feita pela Cuponation ${ }^{5} \mathrm{em} 2019$, com 329 jovens brasileiros na faixa etária dos 17 aos 25 anos, foi constatado que eles passam em média uma hora e meia por dia no Instagram, e de acordo com uma pesquisa feita pelo Statista ${ }^{6}$. Também em 2019, essa mesma rede social fica em $4^{\circ}$ lugar entre as redes sociais mais utilizadas no Brasil, com cerca de 55 milhões de usuários apenas em nosso país.

Sendo esta, então, uma das redes sociais a qual os jovens mais têm acesso, é propícia para nossa pesquisa, pois nela também se fazem presentes textos literários, já que há um leque de possibilidades e conteúdos variados no Instagram. Com relação à forma que o texto ou poesia são publicados nesta rede, devemos entender que "o texto se reconfigura em cada novo meio e suporte que surge da necessidade do homem em se comunicar. No ciberespaço, o texto adquire, em essência, características e potencialidades da rede" (MARTINS, 2016, p. 4).

A poesia digital, mais especificamente no Instagram, tem rompido com o texto poético convencional, com a estrutura do poema em si, pois nesta nova modalidade, há a junção de texto, imagem e post. Então, há uma preocupação com a estética gráfica e visual do que está sendo publicado, assim como há uma preocupação com o texto escrito. Há muito que já existe uma relação forte da linguagem com a imagem:

Palavra e imagem não são mais do que os iluministas sonharam que fossem: meios transparentes através dos quais a realidade se apresenta à compreensão. Elas se tornaram tão enigmáticas, problemas para serem decifrados, quanto é enigmática a realidade que, sempre com certa distorção e ambiguidade, elas intentam representar. (SANTAELLA, 1992, p. 37 apud MARTINS, 2016, p. 5).

E essa relação não é diferente com a poesia, e não se aplica apenas ao contexto digital, já que a poesia concretista e neoconcretista também utilizam imagem e palavra para construir significação e sentido. Por isso, essas poesias também precisam fazer parte do conjunto de textos literários

\footnotetext{
4 Texto, imagem ou mensagem publicada na Internet, em sites ou nas redes sociais. 5 Disponível em: https://www.cuponation.com.br/insights/instagram-2019. Acesso em: 24 ago. 2020. 6 Disponível em: https://www.proxxima.com.br/home/proxxima/noticias/2019/12/09/instagram-ganha-mais-de-230-de-usuarios-em-dois-anos.html. Acesso em: 24 ago. 2020.
} 
estudados pelos alunos, para que eles possam desenvolver uma melhoria na prática de leitura literária e ampliar sua criticidade com relação aos textos que eles têm contato em sua realidade.

\section{As páginas de literatura do Instagram e o acesso à poesia}

É inegável que em nosso século há uma crescente profusão de poetas e escritores ligados diretamente ao meio digital e às novas tecnologias. Assim como há a passagem de obras e textos do impresso ao digital, o inverso também tem ocorrido com grande frequência. Justamente pela crescente participação das pessoas nas redes sociais, onde os novos escritores têm começado a divulgação de textos, e com a popularidade que elas proporcionam, acabam ampliando sua produção para o meio impresso e conseguem o mesmo sucesso e aceitação na realidade, pois seus leitores que passam a ser compradores de suas obras são influenciados com relação ao que consomem também pelo meio digital.

A utilização desses novos espaços tem trazido uma revolução na escrita poética e aberto possibilidades a novos escritores, pessoas que produzem há pouco tempo, pois, as redes sociais, principalmente o Instagram, proporcionam não só visibilidade aos poetas contemporâneos, mas também divulgação. Ele liga as obras aos leitores interessados através das hashtags ${ }^{7}$.

Com relação a esses novos formatos de escrita e divulgação de poesia, podemos compreender que

A tecnologia altera a percepção que temos dos fenômenos, tanto quanto altera os próprios fenômenos. E se não faz hoje sentido dizer que na era da eletricidade a arte se tornou impessoal ou fria, a arte que se produz hoje - feita com outros meios, agora eletrônicos, cibernéticos, desmaterializados - é fruto do trabalho de indivíduos cuja percepção se altera a cada momento que passa. (BACELAR, 2001, p. 31).

Sendo assim, o que se produz hoje condiz com a sociedade tecnológica em que estamos inseridos. A arte, a palavra, a poesia têm sido ressignificadas de acordo com as nuances dessa nova comunidade.

As páginas e perfis no Instagram voltados à poesia, por sua vez, têm tido um grande alcance com poemas que falam de assuntos como amor, saudade, autoestima, ou que se referem à própria linguagem, numa espécie de metalinguística. Além disso, se configuram como poemas curtos e de fácil compreensão, o que chama a atenção do usuário das redes sociais que sempre estão em busca de coisas simples, rápidas e diretas.

Apesar dos "Instapoetas"8 serem um grupo relativamente novos, já existem pioneiros como a Rupi Kaur, escritora dos livros de poesia Outros jeitos de usar a boca e O que sol faz com as flores ${ }^{10}$, que são facilmente encontrados nas listas de livros mais vendidos pelo mundo, que por sua vez também começou a divulgar suas poesias nas redes sociais antes de desaguar no meio impresso.

Um dos poetas contemporâneos que tem ganhado destaque com as poesias autorais no Instagram é o Lucão (@lucaoescritor ${ }^{11}$ ), que começou a escrever na época em que os blogs faziam sucesso e depois migrou para as redes sociais. Com mais de 500 mil seguidores no Instagram, ele publica poemas curtos, e já publicou alguns livros impressos partindo também de sua produção digital.

\footnotetext{
7 Palavra-chave utilizada nas redes sociais antecedida pelo símbolo do jogo da velha (\#) e que através dela os usuários encontram diversas publicações associadas à palavra.

8 Termo utilizado para se referir aos poetas que divulgam seus textos no Instagram.

9 Publicado no Brasil pela Editora Planeta, 2015.

10 Publicado no Brasil pela Editora Planeta, 2017.

11 Instagram “Lucão", disponível em: https://www.instagram.com/lucaoescritor/. Acesso em: 01 ago. 2020.
} 

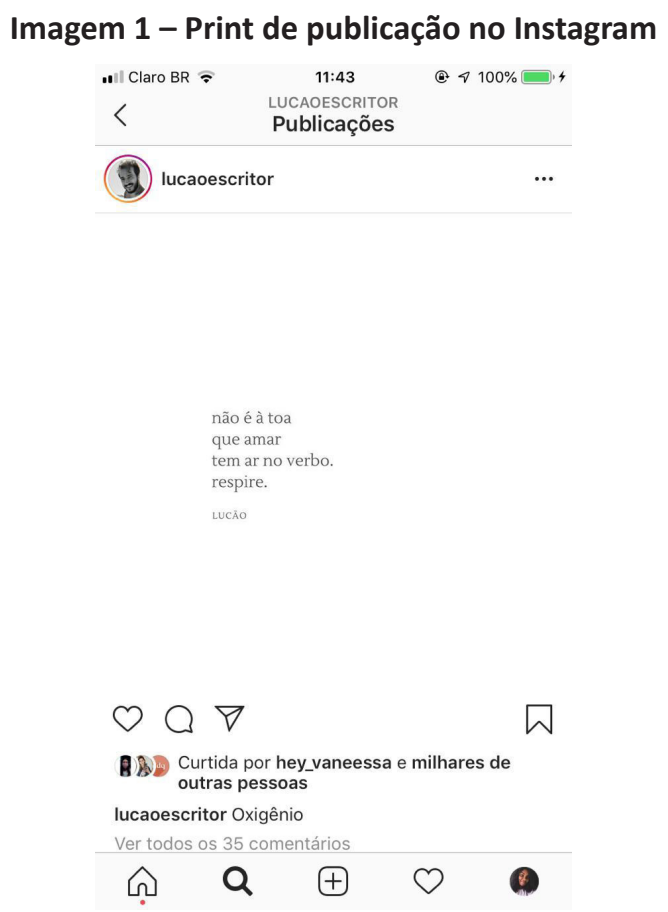

Fonte: Perfil @lucaoescritor no Instagram (2020) $)^{12}$

Imagem 2 - Print de publicação no Instagram

$\begin{array}{cc}\text {-1Il Claro BR }= & \begin{array}{c}11: 44 \\ \text { LUCAOESCRITOR } \\ \text { Publicações }\end{array} \\ \text { (3) lucaoescritor } & \ldots\end{array}$

a saudade

é uma forma de amar

as pessoas que estão

onde a gente não pode

Lucic

$\odot \bigcirc \nabla$

W

D.: Curtida por yasmim_cristinny e milhares de outras pessoas

lucaoescritor É chegar sem ir

Ver todos os 74 comentários

ब $Q$ ๑ 0

Fonte: Perfil @lucaoescritor no Instagram (2020)13

Outro segmento também relacionado à poesia e à literatura no Instagram são os perfis ou páginas que divulgam textos de obras impressas de escritores já conhecidos, como Machado de Assis e Carlos Drummond de Andrade. Esta é outra possibilidade da literatura chegar às pessoas através das redes sociais. Trazer o que muitas vezes os jovens não vão procurar nos livros impressos para o Instagram, como já mencionamos acima, que é uma das redes mais acessadas por eles.

12 Disponível em: https://www.instagram.com/p/B7Du3o7FoQB/. Acesso em: 30 set. 2020

13 Disponível em: https://www.instagram.com/p/CC4q2LrF6Np/. Acesso em: 30 set. 2020. 
A página do Instagram “Literatura é só amor” (@literaturaesoamor ${ }^{14}$ ) dedica-se a publicar fotos de livros com poesias ou pequenos textos de autores brasileiros e estrangeiros para que seus mais de 20 mil seguidores tenham acesso a essas obras e tenham um contato com a literatura no ambiente virtual.

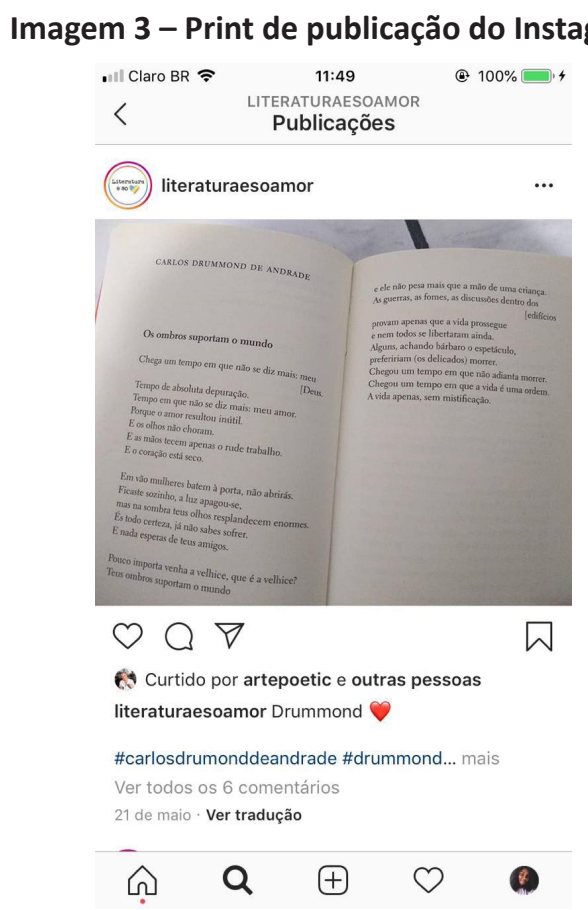

Fonte: Perfil @literaturaesoamor no Instagram (2020) ${ }^{15}$

\section{Imagem 4 - Print de publicação do Instagram}
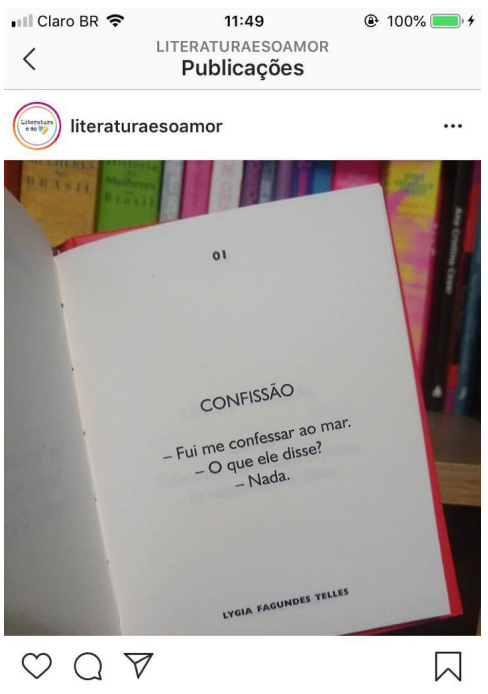

6. Curtida por artepoetic e milhares de outras

literaturaesoamor Lygia Fagundes Telles

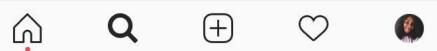

Fonte: Perfil @literaturaesoamor no Instagram (2020) ${ }^{16}$ 


\section{Os desafios e possibilidades do docente na utilização da poesia digital}

Diante de toda essa discussão, surgem diversas questões e problematizações pertinentes: "Quais são os recursos disponíveis para o professor adaptar sua aula?", “Qual a preparação que o professor tem para lidar com as novas tecnologias?", "É oferecida algum tipo de formação docente que o prepare para as novas possibilidades?", entre outros pontos que afligem os docentes ao tentarem sair da metodologia tradicional de ensino.

Na pesquisa que fizemos com alguns docentes de língua portuguesa e literatura e com alguns alunos dos períodos finais do curso de Letras que já estão estagiando em sala de aula, percebemos as dificuldades que permeiam sua prática. Quando questionados sobre a formação para trabalhar com tecnologia em sala de aula, tivemos a seguinte resposta:

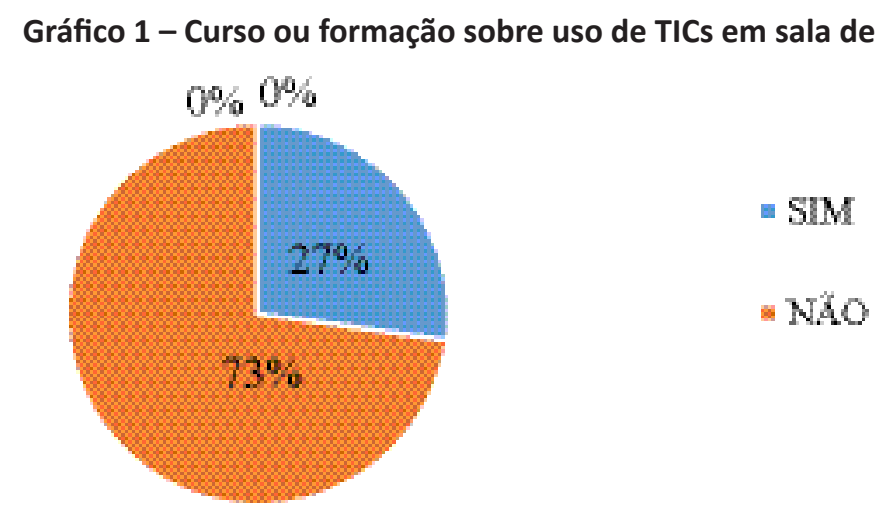

Fonte: Elaborado pela autora.

Do mesmo modo, o percentual dos que não tinham nenhum tipo de curso ou formação nessa área foi exatamente igual aos que responderam que não se sentem preparados de modo algum para agregar as novas tecnologias em sala de aula. Acredita-se que esse é um reflexo da realidade da preparação dos docentes em nosso país. Contudo, a importância disso passa despercebido pelo sistema, pois deixam de lado as mudanças sociais e sua influência na escola. As mudanças fora da sala de aula interferem diretamente nela e na aprendizagem dos alunos, por isso as metodologias ativas têm ganhado tanto espaço e são muito importantes na educação. Compreendemos que

O objetivo do desenvolvimento das metodologias ativas em sala de aula é estimular a autonomia intelectual dos alunos por meio de atividades planejadas. O método ainda conta com o uso das tecnologias como ferramentas para potencializar o aprendizado, num processo que visa estimular a autoaprendizagem e a curiosidade do aluno para pesquisar, refletir e analisar possíveis situações, o que é necessário para uma tomada de decisão assertiva. (SAHAGOFF, 2019, p. 12).

Ou seja, em nossos dias, é praticamente impossível não utilizar de algum meio tecnológico nas nossas metodologias, os próprios discentes cobram essa atualização por parte dos professores e da escola.

É importante salientar que várias outras questões inibem os docentes quanto à utilização de novos métodos, entre eles os nossos entrevistados destacaram o cronograma escolar e o incentivo ao uso integral do livro didático, a falta de autonomia do docente frente a algumas equipes gestoras e principalmente a falta de recursos das escolas, especialmente as públicas. Contudo, as metodologias ativas, para além do uso de tecnologias, é a adaptação que o professor faz do conteúdo com a realidade inerente a sua sala de aula, sendo assim, cabe ao professor adequar e criar com o que lhe é disposto. 
A leitura como um todo é o grande norteador da educação e da escola, apesar da literatura como matéria só estar presente no ensino médio, o conteúdo em si, as obras literárias, os escritores, os gêneros literários, já são estudados desde o ensino fundamental. Destacamos sua primazia no sentido educação e sociedade porque

A leitura é uma maneira de interação social com o mundo e também uma das formas de se obter conhecimento para a produção do saber estruturado e organizado. $\mathrm{O}$ indivíduo ao ler, amplia os diálogos e as fronteiras, alcançando pessoas de diferentes culturas, localidades e pensamentos. (BARROS; OLIVEIRA; COSTA, 2019, p. 11).

A importância de inserir outros meios no ensino de leitura na escola está relacionada diretamente à compreensão social que o aluno terá. A escola é responsável por oferecer uma educação que traga autonomia ao estudante e o transforme em um cidadão, ou seja, que o prepare para o convívio em sociedade e suas nuances. E assim "podemos compreender então, que a função da escola é desenvolver no educando a capacidade de aprender a apreender, organizando as práticas pedagógicas à formação moral e social do indivíduo" (BARROS; OLIVEIRA; COSTA, 2019, p. 12).

Sendo assim, com o advento da internet e redes sociais e sua influência na juventude, faz-se necessário que os docentes se inteirem disso e adequem as suas aulas. Há possibilidades de uso, contudo, falta formação, preparação e recursos, mas faz parte do processo educativo lidar com as mudanças sociais, e os docentes não podem negar isso.

\section{Considerações finais}

Diante de toda essa discussão, entendemos que não há como a escola existir sem a relação com a sociedade e com suas mudanças. As novas tecnologias são apenas uma parte dessas mudanças que, por sua vez, trazem muitos tópicos plausíveis para a discussão e inserção em sala de aula.

Nossa pesquisa e questionário nos levaram a compreender que há uma carência imensa na formação dos docentes para lidar com as demandas de sala de aula, principalmente quando estas estão associadas às atualidades da sociedade. Aplicar poemas do Instagram nas aulas é apenas uma das opções e discussões. Essa defasagem faz com que a metodologia de ensino continue tradicional, ou seja, que a escola continue preparando o aluno, como preparava nos anos passados, para realidades sociais que não existem mais. Com isso, compreendemos a importância da preparação e qualificação do docente, principalmente na área de formação continuada.

As práticas de leitura, bem como a multiplicidade que o letramento abrange, devem fazer parte da formação dos docentes e serem desenvolvidas nas aulas, para que o aluno saia do ensino básico com uma preparação mínima para lidar com as situações sociais que exigirão seu conhecimento.

Vale ressaltar que a escassez de conteúdo nessa área deve ser um dos principais propulsores da pesquisa, faz parte do fazer docente utilizar as metodologias que mais se adequam à sua realidade e adaptá-la. Quando se trata das tecnologias da informação, internet, redes sociais, entre outras coisas, atreladas ao ensino, cabe a cada docente procurar atualizar-se e planejar como será essa aplicação em sua aula e como irá trabalhar com os discentes. 


\section{Referências}

BACELAR, Jorge. Poesia Visual. Covilhã: Universidade da Beira Interior, 2001. Disponível em: http://www.bocc.ubi. pt/pag/bacelar-jorge-poesia-visual.pdf. Acesso em: 24 ago. 2020.

BARROS, Erika Karla da Costa; OLIVEIRA, Priscilla da Costa; COSTA, Daniela da Silva. O professor mediador e formador de leitores. In: ANDRADE, Jacks de Mello Júnior; SOUZA, Liliane Pereira; SILVA, Neidi Liziane Copetti (org.). Metodologias ativas: práticas pedagógicas na contemporaneidade. Campo Grande: Editora Inovar, 2019. p. 153-161.

BRASIL. Ministério da Educação. Base Nacional Comum Curricular. Brasília, DF: MEC, 2017.

COSSON, Rildo. Letramento Literário: uma localização necessária. Letras \& Letras, Uberlândia, v. 31, n. 3, p. 173-187, jul./dez. 2015.

COSSON, Rildo. Letramento Literário: teoria e prática. 2. Ed. São Paulo: Contexto, 2014a.

COSSON, Rildo. Entrevista concedida a Begma Tavares Barbosa. Revista Práticas de Linguagem, Juiz de Fora, v. 4, n. 2, jul./dez. 2014b.

KLEIMAN, Angela B. Os significados do letramento. São Paulo: Mercado de Letras, 2001.

MARTINS, Amanda. Instaliteratura: imagem e palavra em manifestações poéticas no instagram. In: SIMPÓSIO NACIONAL ABCIBER, 9., 2016, São Paulo. Anais [...]. São Paulo: PUCSP, 2016.

SAHAGOFF, Ana Paula da Cunha. Metodologias Ativas: um estudo sobre práticas pedagógicas. In: ANDRADE, Jacks de Mello Júnior; SOUZA, Liliane Pereira; SILVA, Neidi Liziane Copetti (org.). Metodologias ativas: práticas pedagógicas na contemporaneidade. Campo Grande: Editora Inovar, 2019. p. 140-152.

SEVERINO, Antônio Joaquim. Metodologia do Trabalho Científico. 23. ed. São Paulo: Cortez, 2007.

SILVA, Tânia Maria da Conceição Meneses, SANTOS, Vera Lúcia Maia, COELHO, Milton Gomes. De poetas e poesia: do conceito clássico à era digital. In: ENCONTRO INTERNACIONAL DE FORMAÇÃO DE PROFESSORES, 9., 2016, Aracajú. Anais [...]: Aracaju: Unit, 2016. Disponível em: https://eventos.set.edu.br/enfope/article/view/2583. Acesso em: 30 set. 2020 .

SOUZA, Renata Junqueira, COSSON, Rildo. Letramento Literário: uma proposta para a sala de aula. In: UNIVERSIDADE Estadual Paulista "Julio Mesquita Filho"; UNIVERSIDADE Virtual do Estado de São Paulo. Caderno de formação: formação de professores didática dos conteúdos. São Paulo: Cultura Acadêmica, 2011. p. 101-107.

TODOROV, Tzvetan. A literatura em perigo. Tradução Caio Meira. Rio de Janeiro: Difel, 2009.

Data de submissão: 28/01/2021

Data de aceite: $05 / 03 / 2021$ 